\title{
MENGEMBANGKAN PENYELESAIAN NUMERIK PADA SISTEM PERSAMAAN LINIER DENGAN KONSEP ALJABAR
}

\author{
Bambang Agus Sulistyono \\ Pendidikan Matematika Universitas Nusantara PGRI Kediri \\ email: bb7agus1@gmail.com
}

\begin{abstract}
Abstrak
Permasalahan sistem persamaan linear banyak dijumpai dalam persoalan ilmu pengetahuan dan teknologi, seperti pada penyelesaian numerik persamaan diferensial biasa, diferensial parsial, analisis jaringan dan sebagainya. Ukuran yang besar dan bilangan yang terlibat dalam matriks seringkali menjadi kendala dalam menyelesaikan secara analitik. Penyelesaian secara numerik adalah salah satu alternatif yang dapat dilakukan. Dalam mengembangkan kearah numerik, algoritma dibangun dengan konsep aljabar, agar mampu digunakan dalam menyelesaikan sistem persamaan linear secara umum. Dalam paper ini dibahas bagaimana mengkonstruksi algoritma dari bentuk aljabar linier ke perhitungan numerik.
\end{abstract}

Kata kunci : sistem linear, metode langsung, metode iterasi.

\section{PENDAHULUAN}

Sistem persamaan linear muncul hampir di setiap cabang matematika terapan. Dalam beberapa hal persamaan ini muncul langsung dari perumusan awal dari persoalannya, di dalam banyak hal lain penyelesaian dari persamaan merupakan bagian dari pengerjaan beberapa macam persoalan lain. Hal yang menarik adalah bahwa penyelesaian persamaan diferensial parsial sering didekati dengan metode yang membutuhkan penyelesaian sistem persamaan.

Di dalam penyelesaian sistem persamaan akan dicari nilai $x_{1}, x_{2}, \ldots, x_{n}$ yang memenuhi sistem persamaan berikut:

$$
\begin{aligned}
& a_{11} x_{1}+a_{12} x_{2}+\cdots+a_{1 n} x_{n}=b_{1} \\
& a_{21} x_{1}+a_{22} x_{2}+\cdots+a_{2 n} x_{n}=b_{2} \\
& \vdots \quad \vdots \quad \quad \quad \vdots \quad \vdots \\
& a_{n 1} x_{1}+a_{n 2} x_{2}+\cdots+a_{n n} x_{n}=b_{n}
\end{aligned}
$$

dengan $a$ adalah koefisien konstan, $b$ adalah konstan, $n$ adalah jumlah persamaan, dan $x_{1}, x_{2}, \ldots, x_{n}$ adalah bilangan tak diketahui.

Dalam paper ini akan dikaji dua metode numerik untuk menyelesaikan sistem persamaan linier yaitu metode langsung (seperti eliminasi Gauss dan dekomposisi $L U$ ) dan metode iterasi 
(seperti metode iterasi Jacobi dan metode iterasi Gauss-Seidel).

\section{PEMBAHASAN}

\section{Metode Langsung}

\section{a. Eliminasi Gauss}

Metode eliminasi Gauss adalah salah satu metode yang paling awal dikembangkan dan banyak digunakan dalam penyelesaian sistem persamaan linier. Prosedur penyelesaian dari metode ini adalah mengurangi sistem persamaan ke dalam bentuk segitiga atas sedemikian sehingga salah satu dari persamaanpersamaan tersebut hanya mengandung satu bilangan tak diketahui, dan setiap persamaan berikutnya hanya terdiri dari satu tambahan bilangan tak diketahui baru.

Untuk itu terlebih dahulu tuliskan sistem persamaan linier di atas ke dalam bentuk matrik yang diperbesar,

$$
\left[\begin{array}{ccccc}
a_{11} & a_{12} & \cdots & a_{1 n} & a_{1 n+1} \\
a_{21} & a_{22} & \cdots & a_{2 n} & a_{2 n+1} \\
\vdots & \vdots & \cdots & \vdots & \vdots \\
a_{n 1} & \cdots & \cdots & a_{n n} & a_{n n+1}
\end{array}\right]
$$

Kolom ke-n+1 sebagai vektor b. OBE selanjutnya diterapkan untuk membuat nol elemen yang berada di bawah diagonal utama. Untuk membuat nol elemen $a_{21}, a_{31}, \cdots, a_{n 1}$, kita ikuti proses berikut. Operasi penggantian baris ke-2 dengan baris ke-2 ditambah p kali baris ke 1 dilakukan untuk membuat $a_{21}$ menjadi nol. Di sini kita gunakan $p=-a_{21} / a_{11}, \quad a_{11}$ sebagai pembagi disebut elemen pivot. Pada tahap ini algoritma dapat disusun

$$
\begin{aligned}
& \mathrm{p}:=-\mathrm{a}[2,1] / a[1,1] \\
& \text { Untuk } \mathrm{j}:=2,3, \ldots, \mathrm{n}+1 \\
& \qquad a[2, j]:=a[2, j]+p * a[1, j] \\
& a[2,1]:=0
\end{aligned}
$$

Penggantian baris ke-3 dengan baris ke-3 ditambah p kali baris ke 1 dilakukan untuk membuat $a_{31}$ menjadi nol, kita gunakan $\quad p=-a_{31} / a_{11}, \quad$ dengan algoritma

$$
\begin{aligned}
& \mathrm{p}:=-\mathrm{a}[3,1] / a[1,1] \\
& \text { Untuk } \mathrm{j}:=2, \ldots, n+1 \\
& \qquad a[3, j]:=a[3, j]+p * a[1, j] \\
& a[3,1]:=0
\end{aligned}
$$

Penggantian baris ke-4 dan seterusnya dapat dilakukan dengan cara yang sama, sehingga keseluruhan tahap tersebut dapat digabungkan menjadi

$$
\begin{aligned}
& \text { Untuk } i:=2,3, \ldots, n \\
& \text { p:=a[i,1]/a[1,1] } \\
& \text { Untuk j:=2, 3, ., n+1 } \\
& \quad a[i, j]:=a[i, j]-p^{*} a[1, j] \\
& a[i, 1]:=0
\end{aligned}
$$

Sampai di sini kita peroleh matrik perluasan, menjadi 


$$
\left[\begin{array}{ccccc}
a_{11} & a_{12} & \cdots & a_{1 n} & a_{1 n+1} \\
0 & a_{22} & \cdots & a_{2 n} & a_{2 n+1} \\
0 & \vdots & \cdots & \vdots & \vdots \\
0 & a_{n 2} & \cdots & a_{n n} & a_{n n+1}
\end{array}\right]
$$

Tahap berikutnya adalah membuatnol kolom ke-2 (warna merah), dengan algoritma

$$
\begin{aligned}
& \text { Untuk } i:=3, \ldots, n \\
& \mathrm{p}:=\mathrm{a}[\mathrm{i}, 2] / \mathrm{a}[2,2] \\
& \text { Untuk } \mathrm{j}:=3, \ldots, \mathrm{n}+1 \\
& a[i, j]:=a[i, j]- \\
& \mathrm{p}^{*} \mathrm{a}[2, \mathrm{j}] \\
& \mathrm{a}[\mathrm{i}, 2]:=0
\end{aligned}
$$

Begitu seterusnya untuk kolom yang lain, sehingga keseluruhan diperoleh algoritma eliminasi Gauss

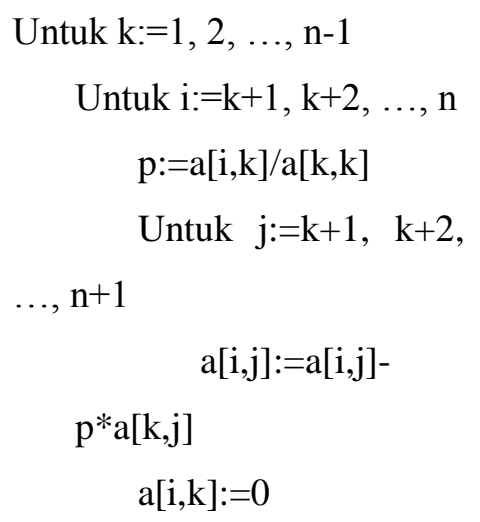

\section{b. Dekomposisi $L U$}

Suatu cara menyelesaikan SPL

$$
A x=b
$$

adalah dengan memecah matrik $A$ menjadi matrik segitiga bawah $L$ dan matrik segitiga atas $U$, lebih khusus lagi $L$ mempunyai elemen 1 pada diagonal utama. Sehingga penyelesaian SPL dalam dua tahap

$$
L y=b, \quad U x=y
$$

$y$ diselesaikan dari SPL pertama, kemudian diikuti menentukan $x$ melalui matrik $U$. Masalah sekarang adalah bagaimana mendekomposisi $A$ menjadi dua matrik $L$ dan $U$, dan membuat algoritma-nya.

Kita ikuti proses dekomposisi untuk matrik ukuran $3 \times 3$ berikut. Diberikan matrik

$$
A:=\left[\begin{array}{lll}
a_{11}^{(1)} & a_{12}^{(1)} & a_{13}^{(1)} \\
a_{21}^{(1)} & a_{22}^{(1)} & a_{23}^{(1)} \\
a_{31}^{(1)} & a_{32}^{(1)} & a_{33}^{(1)}
\end{array}\right]
$$

Kita gunakan superscript (1) untuk menyatakan sebagai notasi awal, dan setelah melalui proses perhitungan tempat yang ada akan ditimpa, karena matrik $L$ dan $U$ akan disimpan pada matrik $A$ tersebut.

Sebagai matrik dekomposisinya kita misalkan mempunyai elemen

$$
L=\left[\begin{array}{ccc}
1 & 0 & 0 \\
m_{21} & 1 & 0 \\
m_{31} & m_{32} & 1
\end{array}\right], \quad U=\left[\begin{array}{ccc}
a_{11} & a_{21} & a_{13} \\
0 & a_{22} & a_{23} \\
0 & 0 & a_{33}
\end{array}\right]
$$

Hasil perkalian

$$
L U=\left[\begin{array}{ccc}
a_{11} & a_{12} & a_{13} \\
m_{21} a_{11} & a_{12} m_{21}+a_{22} & a_{13} m_{21}+a_{23} \\
a_{11} m_{31} & a_{12} m_{31}+a_{22} m_{32} & a_{13} m_{31}+a_{23} m_{32}+a_{33}
\end{array}\right]
$$


disamakan dengan elemen $A$, dan

$a_{33}^{(3)}=a_{33}=a_{33}^{(2)}-m_{32} a_{23}^{(2)}$.

Hasil

ditentukan elemen pada matrik $L$ dan $U$

perhitungan, matrik $L$ dan $U$ diletakkan

baris

pertama:

pada satu matrik

$a_{11}=a_{11}^{(1)}, \quad a_{12}=a_{12}^{(1)}, \quad a_{13}=a_{13}^{(1)}$

baris kedua:

$$
\begin{aligned}
& m_{21}=a_{21}^{(1)} / a_{11}^{(1)}, \quad a_{22}^{(2)}=a_{22}=a_{22}^{(1)}-m_{21} a_{12}^{(1)} \\
& a_{23}^{(2)}=a_{23}=a_{23}^{(1)}-m_{2} \Theta_{k}^{(1)} \text { arang kita lihat proses dekomposisi }
\end{aligned}
$$

$$
\left[\begin{array}{llll}
a_{11}^{(1)} & a_{12}^{(1)} & a_{13}^{(1)} & a_{14}^{(1)} \\
a_{21}^{(1)} & a_{22}^{(1)} & a_{23}^{(1)} & a_{24}^{(1)} \\
a_{31}^{(1)} & a_{32}^{(1)} & a_{33}^{(1)} & a_{34}^{(1)} \\
a_{41}^{(1)} & a_{42}^{(1)} & a_{43}^{(1)} & a_{44}^{(1)}
\end{array}\right]
$$

kita misalkan didekomposisi menjadi

sebagai notasi sementara untuk mewadahi dua suku pertama dari kesamaan $a_{32}^{(1)}=m_{31} a_{12}+m_{32} a_{22}$ pada elemen baris-3 kolom-2, sama halnya $L:=\left[\begin{array}{cccc}1 & 0 & 0 & 0 \\ m_{21} & 1 & 0 & 0 \\ m_{31} & m_{32} & 1 & 0 \\ m_{41} & m_{42} & m_{43} & 1\end{array}\right] \quad U:=\left[\begin{array}{cccc}a_{11} & a_{12} & a_{13} & a_{14} \\ 0 & a_{22} & a_{23} & a_{24} \\ 0 & 0 & a_{33} & a_{34} \\ 0 & 0 & 0 & a_{44}\end{array}\right]$ untuk baris-3 kolom-3. Sehingga $m_{32}$ dapat dihitung menggunakan $m_{32}=a_{32}^{(2)} / a_{22}^{(2)}, \quad$ dan akhirnya

Hasil perkalian keduanya

$$
L U=\left[\begin{array}{cccc}
a_{11} & a_{12} & a_{13} & a_{14} \\
m_{21} a_{11} & m_{21} a_{12}+a_{22} & m_{21} a_{13}+a_{23} & m_{21} a_{14}+a_{24} \\
m_{31} a_{11} & m_{31} a_{12}+m_{32} a_{22} & m_{31} a_{13}+m_{32} a_{23}+a_{33} & m_{31} a_{14}+m_{32} a_{24}+a_{34} \\
m_{41} a_{11} & m_{41} a_{12}+m_{42} a_{22} & m_{41} a_{13}+m_{42} a_{23}+m_{43} a_{33} & m_{41} a_{14}+m_{42} a_{24}+m_{43} a_{34}+a_{44}
\end{array}\right]
$$

Dengan menyamakan $L U$ dan $A$, kita - $\quad m_{21}=a_{21}^{(1)} / a_{11}^{(1)} ; \quad a_{22}^{(2)}=a_{22}^{(1)}-m_{21} a_{12}^{(1)}$ peroleh $a_{23}^{(2)}=a_{23}^{(1)}-m_{21} a_{13}^{(1)}$ - $\quad a_{11}=a_{11}^{(1)}, \quad a_{12}=a_{12}^{(1)}, \quad a_{13}=a_{13}^{(1)}, \quad a_{14}=a_{14}^{(1)}$, $a_{24}^{(2)}=a_{24}^{(1)}-m_{21} a_{14}^{(1)}$ 


$$
\begin{array}{cll}
-m_{31}=a_{31}^{(1)} / a_{11}^{(1)} ; & a_{32}^{(2)}=a_{32}^{(1)}-m_{31} a_{12}^{(1)} \bullet \quad m_{42}=a_{42}^{(2)} / a_{22}^{(2)} ; & a_{43}^{(3)}=a_{43}^{(2)}-m_{42} a_{23}^{(2)} \\
& a_{33}^{(2)}=a_{33}^{(1)}-m_{31} a_{13}^{(1)} & \\
& a_{34}^{(2)}=a_{34}^{(1)}-m_{31} a_{14}^{(1)} &
\end{array}
$$

berkaitan dengan suku warna merah dan

$a_{32}^{(2)}, a_{33}^{(2)}, a_{34}^{(2)} \quad$ merupakan nilai biru pada matrik $L U$. Sampai tahap ini sementara dari elemen pada posisi yang ditunjukkan oleh indek, terkait dengan suku yang berwarna merah pada $L U$. kita sudah menghitung hamper semua elemen $L$ dan $U$, seperti yang ditampilkan pada matrik berikut, warna

$$
\begin{aligned}
& \text { - } \quad m_{41}=a_{41}^{(1)} / a_{11}^{(1)} ; \quad a_{42}^{(2)}=a_{42}^{(1)}-m_{41} a_{12} \\
& \begin{array}{l}
a_{43}^{(2)}=a_{43}^{(1)}-m_{41} a_{13}^{(1)} \\
a_{44}^{(2)}=a_{44}^{(1)}-m_{41} a_{14}^{(1)}
\end{array}\left[\begin{array}{llll}
a_{11}^{(1)} & a_{12}^{(1)} & a_{13}^{(1)} & a_{14}^{(1)} \\
m_{21} & a_{22}^{(2)} & a_{23}^{(2)} & a_{24}^{(2)} \\
m_{31} & m_{32} & a_{33}^{(3)} & a_{34}^{(3)} \\
m_{41} & m_{42} & a_{43}^{(3)} & a_{44}^{(3)}
\end{array}\right]
\end{aligned}
$$

$a_{42}^{(2)}, a_{43}^{(2)}, a_{44}^{(2)} \quad$ merupakan nilai sementara dari elemen pada posisi yang ditunjukkan oleh indek, terkait dengan suku yang berwarna merah pada $L U$.

Sampai tahap ini, matrik yang diperoleh, $L$ dan $U$ disimpn dalam matrik $A$,

$$
\left[\begin{array}{llll}
a_{11}^{(1)} & a_{12}^{(1)} & a_{13}^{(1)} & a_{14}^{(1)} \\
m_{21} & a_{22}^{(2)} & a_{23}^{(2)} & a_{24}^{(2)} \\
m_{31} & a_{32}^{(2)} & a_{33}^{(2)} & a_{34}^{(2)} \\
m_{41} & a_{42}^{(2)} & a_{43}^{(2)} & a_{44}^{(2)}
\end{array}\right]
$$

Baris pertama dan kedua sudah selesai diolah, begitu juga dengan kolom pertama (warna hijau). Baris ke tiga dan ke empat perlu disempurnakan. Untuk itu kita lakukan perhitungan
Dua elemen tersisa dihitung sebagai berikut

$$
\text { - } \quad m_{43}=a_{43}^{(3)} / a_{33}^{(3)} ; \quad a_{44}^{(4)}=a_{44}^{(3)}-m_{43} a_{34}^{(3)}
$$

Sehingga diperoleh

$$
\left[\begin{array}{llll}
a_{11}^{(1)} & a_{12}^{(1)} & a_{13}^{(1)} & a_{14}^{(1)} \\
m_{21} & a_{22}^{(2)} & a_{23}^{(2)} & a_{24}^{(2)} \\
m_{31} & m_{32} & a_{33}^{(3)} & a_{34}^{(3)} \\
m_{41} & m_{42} & m_{43} & a_{44}^{(4)}
\end{array}\right]
$$

Dengan mengikuti proses dekomposisi dari matrik $3 \times 3$ dan $4 \times 4$, diharapkan dapat memberikan pola berpikir untuk mendekomposisikan matrik ukuran nxn. Sedangkan eksistensi $\begin{aligned} m_{32}=a_{32}^{(2)} / a_{22}^{(2)} ; & a_{33}^{(3)}=a_{33}^{(2)}-m_{\text {dax }} a_{2 \mathrm{fek}}^{(2)} \\ & a_{34}^{(3)}=a_{34}^{(2)}-m_{1} a_{21}^{(2)} \text { Anton \& R Rorres, Elementary }\end{aligned}$ Linear Alg., hal. 479), yaitu: 
Jika $A$ matrik bujur sangkar yang dapat direduksi menjadi bentuk eselon baris $U$ dengan eliminasi Gauss tanpa penukaran baris, maka $A$ dapat difaktorkan sebagai $A=L U$, dengan $U=E_{m} E_{m-1} \cdots E_{2} E_{1} A, \quad L=E_{1}^{-1} E_{2}^{-1} \cdots E_{m}^{-1}$ ; $E_{1}, E_{2}, \cdots, E_{m}$ matrik elementer yang berkaitan dengan operasi baris.

Berikut langkah-langkah dekomposisi pada matrik ukuran nxn:

- $\quad a_{11}=a_{11}^{(1)}, a_{12}=a_{12}^{(1)}, \cdots, a_{1 n}=a_{1 n}^{(1)}$

- Untuk $\mathrm{p}=1,2, \ldots, \mathrm{n}$

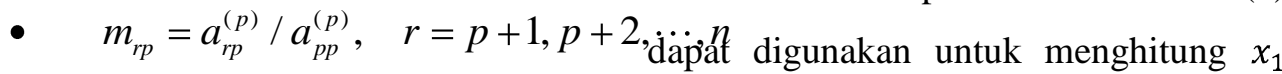
$a_{r c}^{(p+1)}=a_{r c}^{(p)}-m_{r p} a_{p c}^{(p)}, \quad c=p+1$, pebagai $\cdots, n_{\text {fungsi }} \quad$ dari $\quad x_{2}, x_{3}, \ldots, x_{n}$.

Matrik yang diperoleh

$$
\begin{aligned}
& {\left[\begin{array}{lllll}
a_{11}^{(1)} & a_{12}^{(1)} & a_{13}^{(1)} & \cdots & a_{1 n}^{(1)} \\
m_{21} & a_{22}^{(2)} & a_{23}^{(2)} & \cdots & a_{2 n}^{(2)} \\
m_{31} & m_{32} & a_{33} & \cdots & a_{3 n}^{(3)} \\
\vdots & & & \ddots & \vdots \\
m_{n 1} & m_{n 2} & m_{n 3} & \cdots & a_{n n}^{(n)}
\end{array}\right]} \\
& x_{1}=\left[b_{1}-a_{12} x_{2}+a_{13} x_{3}+\cdots+a_{1 n} x_{n}\right] / a_{11} \\
& x_{2}=\left[b_{2}-a_{21} x_{1}+a_{23} x_{3}+\cdots+a_{2 n} x_{n}\right] / a_{22} \\
& x_{n}=\left[b_{n}-a_{n 1} x_{1}+a_{n 2} x_{2}+\cdots+a_{n n-1} x_{n-1}\right] / a_{n n}
\end{aligned}
$$
sebagai fungsi dari $x_{1}, x_{3}, \ldots, x_{n}$, demikian seterusnya sehingga didapat :

Warna kuning merupakan elemen dari $U$ dan sisanya elemen dari $L$ dengan diagonal utama bernilai satu.

\section{Metode Iterasi}

Dalam proses iterasi, masingmasing persamaan yang ada dihitung nilai perkiraan awal dari satu variabel yang tidak diketahui, dengan menggunakan nilai perkiraan sebelumnya. Perhitungan ini diulang terus dengan harapan iterasi berikutnya akan lebih dekat ke solusi sebenarnya.

Persamaan pertama dari Sistem (1) Persamaan kedua untuk menghitung $x_{2}$

kanan dari sistem Persamaan (2). Selanjutnya nilai variabel yang didapat tersebut disubstitusikan ke ruas kanan dari Sistem (2) lagi untuk mendapatkan nilai perkiraan kedua. Prosedur tersebut
Hitungan dimulai nilai perkiraan awal sebarang untuk variabel yang dicari (biasanya semua variabel diambil sama dengan nol). Nilai perkiraan awal tersebut disubstitusikan ke dalam ruas 
diulangi lagi sampai nilai setiap variabel iterasi ke $n$-1. Persamaan (2) dapat ditulis pada iterasi ke $n$ mendekati nilai pada menjadi :

$$
\begin{aligned}
& x_{1}^{(k+1)}=\left[b_{1}-a_{12} x_{2}^{(k)}+a_{13} x_{3}^{(k)}+\cdots+a_{1 n} x_{n}^{(k)}\right] / a_{11} \\
& x_{2}^{(k+1)}=\left[b_{2}-a_{21} x_{1}^{(k)}+a_{23} x_{3}^{(k)}+\cdots+a_{2 n} x_{n}^{(k)}\right] / a_{22} \\
& \vdots \\
& x_{n}^{(k+1)}=\left[b_{n}-a_{n 1} x_{1}^{(k)}+a_{n 2} x_{2}^{(k)}+\cdots+a_{n n-1} x_{n-1}^{(k)}\right] / a_{n n}
\end{aligned}
$$

Superskript $k$ pada $x$ menyatakan banyak-nya iterasi yang telah dilakukan. Tentunya rumus iterasi tersebut dibentuk dengan memilih elemen diagonalnya tidak boleh nol. Bila ada yang nol, maka sistem persamaan linier perlu diubah lebih dahulu urutan persamaannya. Iterasi diatas dikenal sebagai metode Jacobi, dan penghentian iterasi dilakukan dengan

$$
\max _{1 \leq i \leq n}\left|x_{i}^{(k+1)}-x_{i}^{(k)}\right|<\text { Tol }
$$

dapat juga digunakan nilai relatifnya

$$
\max _{1 \leq i \leq n}\left|\frac{x_{i}^{(k+1)}-x_{i}^{(k)}}{x_{i}^{(k+1)}}\right|<\text { Tol }
$$

Di dalam metode Jacobi, nilai $x_{1}$ yang dihitung dari persamaan pertama tidak digunakan untuk menghitung nilai $x_{2}$ dengan persamaan kedua. Demikian

$$
\begin{aligned}
& x_{1}^{(k+1)}=\left[b_{1}-a_{12} x_{2}^{(k)}+a_{13} x_{3}^{(k)}+\cdots+a_{1 n} x_{n}^{(k)}\right] / a_{11} \\
& x_{2}^{(k+1)}=\left[b_{2}-a_{21} x_{1}^{(k+1)}+a_{23} x_{3}^{(k)}+\cdots+a_{2 n} x_{n}^{(k)}\right] / a_{22} \\
& x_{3}^{(k+1)}=\left[b_{2}-a_{31} x_{1}^{(k+1)}+a_{32} x_{3}^{(k+1)}+a_{34} x_{4}^{(k)}+\cdots+a_{2 n} x_{n}^{(k)}\right] / a_{33} \\
& \vdots \\
& x_{n}^{(k+1)}=\left[b_{n}-\left(a_{n 1} x_{1}^{(k+1)}+a_{n 2} x_{2}^{(k+1)}+\cdots+a_{n n-1} x_{n-1}^{(k+1)}\right] a_{n n}\right.
\end{aligned}
$$

Pada saat menghitung $x_{1}^{(k+1)}$ kita $x_{2}^{(k+1)} \quad$ kita gunakan $\quad x_{2}^{(k)}, x_{3}^{(k)}, x_{4}^{(k)}, \cdots, x_{n}^{(k)}, \quad$ pada $\quad x_{1}^{(k+1)}, x_{3}^{(k)}, x_{4}^{(k)}, \cdots, x_{n}^{(k)}$, gunakan hasil 
perhitungan sebelumnya digunakan pada tahap ini, begitu juga untuk menghitung $x_{3}^{(k+1)}$ menggunakan $x_{1}^{(k+1)}, x_{2}^{(k+1)}, x_{4}^{(k)}, \cdots, x_{n}^{(k)}, \quad$ semakin ke bawah semakin banyak hasil iterasi ke$\mathrm{k}+1$ yang digunakan.

Agar iterasi konvergen metoda Jacobi dan juga Gauss-Seidel mengharuskan matrik koefisiennya diagonal dominant, yaitu $\left|a_{i i}\right| \geq \sum_{\substack{j=1 \\ j \neq i}}^{n}\left|a_{i j}\right|$.

\section{DAFTAR PUSTAKA}

Djojodihardjo, H, 2000, Metode Numerik, Penerbit PT Gramedia Pustaka Utama.

L.H. Wiryanto, 2014, Metoda Numerik Pada Sistem Persamaan Linier, disampaikan pada kuliah tamu di UNP Kediri.

Triatmodjo, B, 2002, Metode Numerik dilengkapi dengan program komputer, Beta Offset.

Kondisi ini merupakan syarat cukup, yaitu bila dipenuhi maka iterasi konvergen, tetapi bila tidak dipenuhi masih dimungkinkan konvergen, dengan lambat.

\section{KESIMPULAN}

Sistem persamaan yang banyak dijumpai bersifat 'jarang' dan banyak koefisien yang merupakan nol. Dalam hal ini cara iterasi lebih baik. Sistem persamaan ini banyak dijumpai pada persamaan diferensial. Sistem persamaan yang banyak, bila diselesaikan dengan eliminasi akan kurang teliti dan membutuhkan tempat yang banyak bila diprogram pada komputer. 